\title{
Abnormalities of the blink reflex in Gilles de la Tourette syndrome
}

\author{
S J M SMITH, * A J LEES $†$ \\ From the Departments of Clinical Neurophysiology* and Neurology, $\dagger$ The National Hospital for Nervous \\ Diseases, London, UK
}

SUMmARY The blink reflex and it's recovery cycle were studied in 26 patients with Gilles de la Tourette syndrome and 10 controls. There was a significant increase in the mean duration of the R2 response. The amplitude of the $R 2$ response following paired shocks (mean $R 2[T] / R 2[C] \%$ ) was $11 \%$, $40 \%$ and $52 \%$ of the conditioning stimulus with intervals of $200 \mathrm{~ms}, 500 \mathrm{~ms}$ and 1 second in the patients, compared with $10 \%, 17 \%$ and $32 \%$ respectively in the controls. Half the patients, however, had normal recovery cycles and voluntary suppression of tics and blinks reduced the amplitude of R2 in all patients. These results suggest increased excitability of brainstem interneurons in Gilles de la Tourette syndrome.

Gilles de la Tourette syndrome is a neurobehavioural disorder characterised by multiple tics which must involve both the voice and a body part, usually the head or neck. Copro-and echo-phenomena occur in about a quarter of cases and there is a high incidence of anxiety, obsessional-compulsive behaviour and attention deficit disorder.

Subtle neurophysiological abnormalities have recently been reported. These include abnormalities of the N1-P2 component ( $90-280 \mathrm{~ms})$ of the event related potential in an auditory discrimination task ${ }^{1}$ and reduced slow negative wave, increased postimperative negative variation and marked asymmetry with decreased P4 negativity on contingent negative variation (CNV). ${ }^{2}$ Abnormalities of sleep patterns have also been described, which would be compatible with a primary disorder of arousal. ${ }^{3}$ We now report loss of habituation of the blink reflex in some patients with Gilles de la Tourette syndrome.

\section{Materials and methods}

The blink reflex was studied in 10 normal volunteers with no history of neurological disease ( 6 male, 4 female; mean age 34.7 years) and 26 patients with Gilles de la Tourette syndrome ( 20 male, 6 female; mean age 25.4 years). Disease duration ranged from 2 to 44 years (mean 17.9 years). Twelve were on neuroleptic treatment (2-haloperidol, 6-sulpiride, 1-

Address for reprint requests: Dr A J Lees, The National Hospital for Nervous Diseases, Queen Square, London WCIN 3BG, UK.

Received 28 October 1988 and in revised form 30 January 1989. Accepted 6 February 1989 chlorpromazine, 1-chloprothixene) and one was on a benzodiazepine preparation at the time of study.

The blink reflex was recorded using silver/silver chloride surface electrodes, with the active electrode placed over the orbicularis oculi muscle just below the outer canthus of the eye and the reference on the side of the nose, recording from both eyes simultaneously. The ground electrode was placed on the hand. The reflex was elicited by percutaneous stimulation of the supraorbital nerve. Stimulus intensity was set at a level $50 \%$ above that which elicited a just recognisable response. Responses were amplified and recorded using a Medelec electromyograph; band pass of the amplifier was 32 $\mathrm{Hz}-3 \cdot 2 \mathrm{KHz}$. All subjects were studied lying on a couch in a semi-reclined position.

Initially, single shocks were given to measure the latency of the R1 (early) and ipsilateral and contralateral R2 (late) components, amplitude of $\mathrm{R} 1$ and duration of $\mathrm{R} 2$. At least five single shocks were given. The amplitude of the R1 component of each trial was measured from peak to peak and an average amplitude calculated.

\section{Habituation or recovery cycle of $R 2$}

To assess the recovery cycle of $\mathrm{R} 2$, paired shocks with an interval of $500 \mathrm{~ms}$ and 1 second between the conditioning and test stimulus were delivered in all subjects. The normal volunteers and a small number of patients also had the recovery cycle assessed with interstimulus intervals of 100 and $200 \mathrm{~ms}$. At least five trials at each interstimulus interval were given, with at least 10 seconds between each trial. The amplitude (maximum peak to peak) of the R2 elicited by the test stimulus (R2[T]) was expressed as a percentage of that elicited by the conditioning stimulus (R2[C]) for each trial, and an average $\mathrm{R} 2[\mathrm{~T}] / \mathrm{R} 2[\mathrm{C}] \%$ calculated for each interval.

The recovery cycle was assessed in all subjects at rest, with the eyes open, and then with voluntary suppression of blinks, and in the patients, their facial, body and vocal tics. 


\section{Results}

Latencies of the blink reflex components were similar in the control and patient groups. The mean R1 latency was $10.1 \mathrm{~ms}$ (range 9-11, SD 0.88) in the normal subjects and $10.2 \mathrm{~ms}$ (range 9-12, SD 0.94) in the patients. The mean latency of the ipsilateral and contralateral R2 was 32.7 ms (range 29-38, SD 2.9) and $33.8 \mathrm{~ms}$ (range $24-40$, SD 4.7 ) respectively for the normal subjects and $33.6 \mathrm{~ms}$ (range 28-43, SD 3.6) and $35 \mathrm{~ms}$ (range 19-42, SD 4.3) respectively for the patient group.

The mean amplitude of the $\mathrm{R} 1$ component in the normal subjects was $231 \mu \mathrm{V}$ (range 105-330 $\mu \mathrm{V}$, SD $91 \cdot 1)$, compared with a mean R1 amplitude in the patients of 210 microvolts (range $80-530 \mu \mathrm{V}, \mathrm{SD}$ 116.7); this difference was not significant. Spread of R1 to the contralateral side was seen in two patients and inconsistently in one normal subject. The duration of the $\mathbf{R} 2$ component ranged from $24-40$ ms (mean $33 \cdot 8$, SD 4.68) in the normal subjects and from $29-48 \mathrm{~ms}$ (mean 38.8, SD 4.66) in the patients; the mean duration in the patients was significantly longer $(\mathrm{p}<$ $0 \cdot 005$, Student's $t$ test).

\section{Blink reflex recovery cycle}

The mean time course of the recovery cycle of the blink reflex at rest for all subjects is shown in fig la. A typical response from a normal subject and a patient to paired stimuli with an interstimulus interval of $500 \mathrm{~ms}$ is shown in fig 2 . In the normal subjects, the amplitude of the $\mathbf{R} 2$ response elicited by the test stimulus was $10 \%$ of that elicited by the conditioning stimulus when the interval between the stimuli was $200 \mathrm{~ms}, 17 \%$ when the interval was $500 \mathrm{~ms}$ and $32 \%$ when the interval was 1 second. At a $100 \mathrm{~ms}$ interval, there was no discernible $\mathrm{R} 2$ elicited by the test stimulus in any of the normal subjects.

In the patient group, the corresponding R2 amplitudes were $11 \%, 40 \%$ and $52 \%$. The mean R2 amplitudes elicited by the test stimulus when given 500 $\mathrm{ms}$ and 1 second after the conditioning stimulus in the patients were significantly larger ( $\mathrm{p}<0.05$, Student's $t$ test) than those in the normal subjects. However, from fig 3, which shows the distribution of values for R2[T]/ $\mathrm{R} 2[\mathrm{C}] \%$ for all subjects at $500 \mathrm{~ms}$ and 1 second, it can be seen that there is considerable overlap between the normal and patient groups. About half of the patients had normal blink reflex recovery cycles. In one patient, there was no discernible $\mathbf{R} 2$ elicited by the test stimulus at $500 \mathrm{~ms}$ and at 1 second in another. This was not seen in any of the normal subjects. Three patients showed an abnormal recovery cycle at the 1 second interval only.

Effect of voluntary suppression on the recovery cycle The effect of suppression of tics and blinks on the
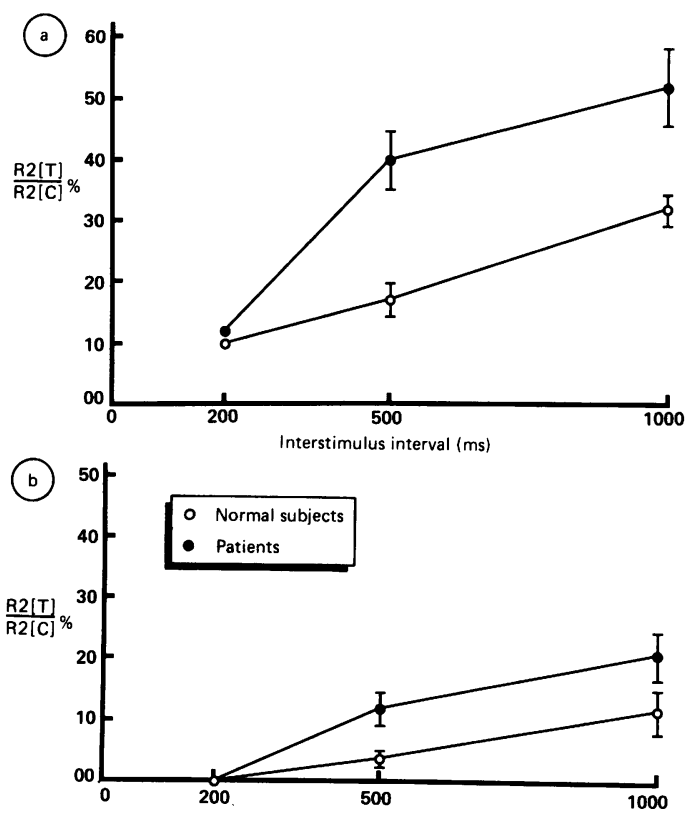

Fig 1 (a) Recovery cycle for $R 2$ without suppression of blinks or tics in all subjects. Mean amplitude $( \pm 1 S E)$ of the test $R 2$ expressed as a percentage of the conditioning $R 2$ is given for each interstimulus interval $(200,500 \mathrm{~ms}, 1$ second). (b) Recovery cycle for $R 2$ in all subjects with voluntary suppression of blinks in normal subjects and voluntary suppression of tics and blinks in patients.

recovery cycle could not be assessed in four patients because of language difficulties (one patient) or unsuccessful suppression. The mean time course of the recovery cycle with voluntary suppression for all subjects is shown in fig $\mathrm{lb}$. With voluntary suppression

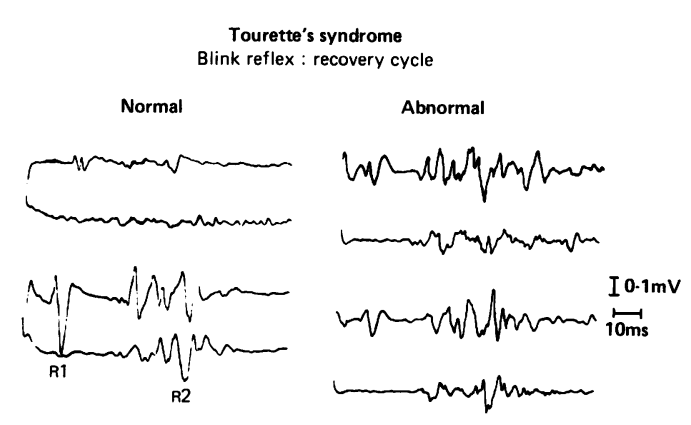

Fig 2 A typical response from a normal subject (left) and a patient (right) at an interstimulus interval of $500 \mathrm{~ms}$. The upper pair of EMG traces are the responses elicited by the test stimulus and the lower pair, the responses elicited by the conditioning stimulus. Recordings from the ipsilateral orbicularis oculi are above those from the contralateral orbicularis muscle in each trace. 


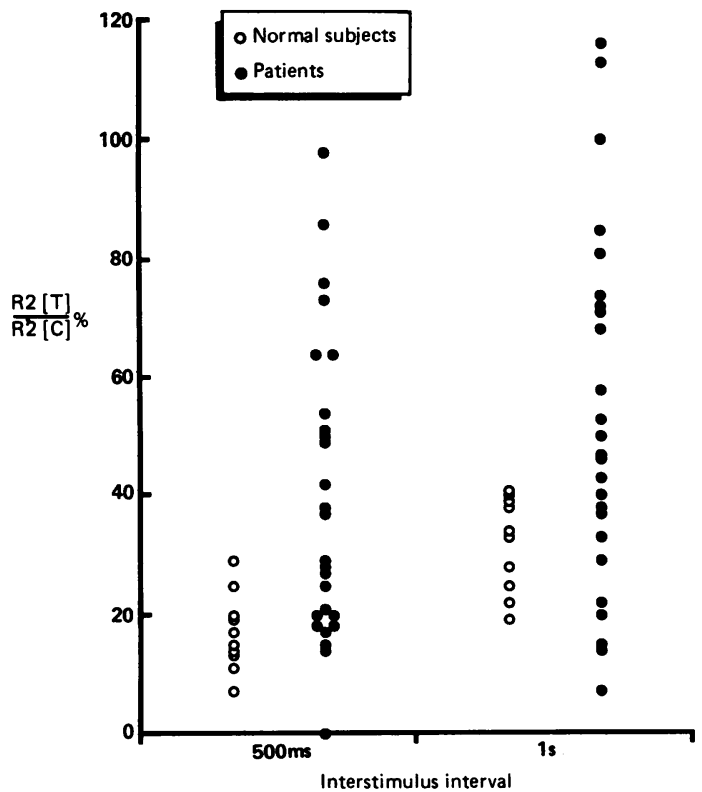

Fig 3 Mean $R 2[T] / R 2[C] \%$ values for all subjects at interstimulus intervals of $500 \mathrm{~ms}$ and 1 second.

of blinks in the normal subjects, there was a reduction in the mean R2[T]/R2[C]\% to 0 at $200 \mathrm{~ms}, 3.7$ (SD $4 \cdot 27$, range $0-13$ ) at $500 \mathrm{~ms}$ and 11.8 (SD 13.34, range $0-33)$ at 1 second. In the patient group, there was also a reduction, to 0 at $200 \mathrm{~ms}, 12.4$ (SD 13.4, range 0-49) at $500 \mathrm{~ms}$ and $20 \cdot 86$ (SD 17.6, range 0-54) at 1 second. The mean conditioned $R 2$ amplitude in the patient group remained significantly larger $(p<0.05$, Student's $t$ test) than that in the normal subjects.

In three of the normal subjects and five of the patients, there was complete suppression of the conditioned R2 at both $500 \mathrm{~ms}$ and 1 second intervals.

The paired stimuli did not affect the amplitude of the $R 1$ component either with or without voluntary suppression of blinks and tics.

\section{Effect of drugs}

Of the two patients on haloperidol, one showed a normal and the other an abnormal recovery cycle. Four of the six patients on sulpiride showed abnormal habituation. One of the two remaining patients on neuroleptic treatment showed a slightly abnormal recovery cycle at an interstimulus interval of 1 second. Since the numbers of patients on each drug were small, these data were not analysed further.

\section{Discussion}

This study has shown an increase in the duration of the
R2 component of the blink reflex and an abnormality of its recovery cycle in patients with Gilles de la Tourette syndrome. Characteristics of the R1 component, in contrast, did not differ between the normal subjects and patients.

The two components of the blink reflex are known to be mediated by different pathways. Although these are not completely understood, the $\mathbf{R} 1$ component is thought to be relayed from the supraorbital nerve to the ipsilateral facial nucleus via a simple oligosynaptic pathway in the pons. ${ }^{4}$ Impulses giving rise to the R2 component descend to the ipsilateral spinal trigeminal tract and are eventually carried to the ipsilateral and contralateral facial nuclei through a polysynaptic pathway in the medulla. ${ }^{5}$ An abnormal recovery cycle of the $\mathbf{R} 2$ component is thought to indicate an increase in the excitability of interneurons subserving this part of the reflex, whereas the recovery cycle of $R 1$ predominantly reflects excitability at the facial motoneuron level. ${ }^{6}$

Abnormalities of the blink reflex recovery cycle have been found in a number of diseases which affect the basal ganglia. Habituation is reduced in Parkinson's disease, ${ }^{7}$ dystonia ${ }^{8}$ and essential blepharospasm, ${ }^{9}$ and is enhanced in Huntington's chorea. ${ }^{10}$ This suggests that there is an important input from the basal ganglia to the pathways in the pons and medulla subserving the blink reflex. Although the pathophysiology of Gilles de la Tourette syndrome is unknown, there is circumstantial evidence implicating basal ganglia structures. Obeso and colleagues ${ }^{11}$ were able to show that there is no Bereitschaft's potential preceding a tic, suggesting that it is not generated in the same way as a self-willed cortically generated movement. Absent dynorphine-like immunoreactivity has recently been found in the dorsal part of the external segment of the globus pallidus in the brain of a patient with Gilles de la Tourette's syndrome. ${ }^{12}$

In addition to the presumed input from basal ganglia, there are other descending influences on the blink reflex. Unilateral hemispheric lesions affect the blink reflex; $;^{1314}$ in acute strokes, Kimura and colleagues found a reduction in amplitude of both the $R 1$ and $R 2$ components and an increased duration of R2, which was interpreted as indicating diffuse dysfacilitation of synapses. ${ }^{15}$ With voluntary suppression of blinks in our normal subjects, and blinks and tics in the patients, there was a reduction in the amplitude of the R2 elicited by the test stimulus, suggesting a powerful inhibitory influence from cortical structures. Reduction in habituation of the blink reflex during voluntary tic inhibition in Gilles de la Tourette syndrome has also been described by Tolosa et al. ${ }^{16}$ It is also possible that a voluntary blink may condition an electrically elicited blink in a similar way to the use of paired electrical stimuli. 
Of interest was the finding of a normal recovery cycle in about half of the patients. There were no obvious clinical differences between these patients and the group with abnormal habituation. The mean duration of symptoms did not differ in the two groups, nor did the severity of symptoms. Patients with tics predominantly involving the limbs were just as likely to have abnormal habituation as patients with tics involving mainly facial musculature. Some of the patients were on treatment at the time of study; there was, however, no obvious effect of any of the drugs used on the recovery cycle. None of the patients had any features to suggest a drug induced Parkinsonian syndrome, which may have affected the recovery cycle.

The reason why the recovery cycle was normal in some patients is unclear; one possible explanation is that there may be a greater descending cortical inhibitory influence in these patients due to conscious suppression of their tics, perhaps as a result of being in an unfamiliar environment during the test. Three patients who were recalled for further testing showed less habituation on the second study.

The finding of an abnormal blink recovery cycle in Gilles de la Tourette syndrome suggests enhanced excitability of brain stem interneurons, possibly due to a disturbance of input from the basal ganglia.

\section{References}

1 van de Wetering BJM, Maartens CMC, Fortgens C, Slaets JPJ, van Woerkom TCAM. Late components of the auditory evoked potentials in Gilles de la Tourette syndrome. Clin Neurol Neurosurg 1985;87:181-6.

2 van Woerkom TCAM, Fortgens C, van de Wetering BJM, Martens CMC. Contingent negative variation in adults with Gilles de la Tourette syndrome. J Neurol Neurosurgery Psychiatry 1988;51:630-4.

3 Glaze DG, Frost JD, Jankovic J. Sleep in Gilles de la Tourette's syndrome: disorder of arousal. Neurology 1983;33:586-92.
4 Shahani BT, Young RR. Human orbicularis oculi reflexes. Neurology 1972;22:149-54.

5 Kimura J, Lyon LW. Orbicularis oculi reflex in Wallenberg syndrome: alteration of the late reflex by lesions of the spinal tract and nucleus of the trigeminal nerve. $J$ Neurol Neurosurgery Psychiatry 1972;35:228-33.

$6 \mathrm{Kimura} \mathrm{J}$. Blink reflex in facial dyskinesia. In: Advances in Neurology, vol 49: Facial Dyskinesia. Jankovic J, Tolosa E, eds. New York: Raven Press, 1988.

7 Kimura J. Disorders of interneurons in parkinsonism: the orbicularis oculi reflex to paired stimuli. Brain 1973;96:87-96.

8 Tolosa E, Montserrat L, Bayes A. Blink reflex studies in patients with focal dystonias. In: Adv in Neurology Vol 50. Dystonia 2. Fahn S, ed. New York: Raven Press, 1988:517-24.

9 Berardelli A, Rothwell JC, Day BL, Marsden CD. Pathophysiology of blepharospasm and oromandibular dystonia. Brain 1985;108:593-608.

10 Caracerri T, Aranzini G, Spreafico R, Negri S, Broggi G, Girotti F. Study of the excitability cycle of the blink reflex in Huntington's chorea. Eur Neurol 1976;14: 465-72.

11 Obeso JA, Rothwell JC, Marsden CD. Simple tics in Gilles de la Tourette's syndrome are not prefaced by a normal premovement EEG potential. $J$ Neurol Neurosurgery Psychiatry 1981;44:735-8.

12 Haber SN, Kowall NW, Vonsattel JP et al. Gilles de la Tourette syndrome. A postmortem neuropathological and immunohistochemical study. $J$ Neurol Sci 1986;75:225-41.

13 Berardelli A, Accornero N, Cruccu G, Fabriano F Guerrisi V, Manfredi M. The orbicularis oculi response after hemispheric damage. $J$ Neurol Neurosurgertê Psychiatry 1983;46:837-43.

14 Dehen H, Willer JC, Bathieu N, Cambier J. Blink reflex in hemiplegia Electroencephalogr Clin Neurophysiol 1976;40:393-400.

15 Kimura J, et al. Blink reflex in cerebrovascular accidents. J Neurol Sci 1985;67:15-28.

16 Tolosa ES, Montserrat L, Bayes A. Reduction of brainstem interneuron excitability during voluntary tic inhibition in Tourette's syndrome. Neurology 1986;36 (suppl): 118 . 